\title{
Do findings from new trials for schizophrenia fit with existing evidence: not duped ... just beguiled?
}

\author{
CLIVE E. ADAMS and MAHESH JAYARAM
}

\begin{abstract}
No treatment has caused a greater revolution in the treatment of people with schizophrenia than chlorpromazine. The new generation of drugs has been embraced by psychiatry with an enthusiasm fostered by the unmet needs of both patients and industry. Recent, independently funded trials have highlighted already existing data illustrating how the new antipsychotics drugs are an additional advance but not a revolution. In this story there are lessons for psychiatry - to opt for science rather than seduction.
\end{abstract}

Only 60 years ago there were almost no pharmacological managements for people with schizophrenia. ECT and other physical treatments were used but nothing was as successful as chlorpromazine. This drug did revolutionise the care of people with schizophrenia worldwide (Freeman, 1958) and assured chlorpromazine's place in medical history (Turner, 2007). Shortly after chlorpromazine came haloperidol and many other antipsychotics, often with the promise of being equally clinically effective but with different side effect profiles, and this, indeed, seemed to be the case (Joy et al., 2006; Marques et al., 2004). Depot formulations were a further advance in means of administration but they never replicated chlorpromazine's initial revolution.

The trial-based evidence of the 1960s and 1970s is of variable quality and limited perspective (Thorley \& Adams, 1998). It is, however, easy to judge the past by standards of today. The first CONSORT statement, encouraging better reporting of trials, is only a decade old (Begg et al., 1996). Nevertheless, recent objective summaries of all trial-based evidence of older antipsychotics highlights compelling evidence of the short term benefits as regards delusions, hallucinations and thought disorder, and variable adverse effects (Hartung et al., 2005; Joy et al., 2006; Matar \& Almerie, 2007; Soares et al., 2000;

\footnotetext{
Address for correspondence: Dr. C.E. Adams, Co-ordinating Editor, Cochrane Schizophrenia Group, Division of Psychiatry, University of Nottingham, Duncan MacMillan House, Portchester Road, Nottingham NG3 6AA, (United Kingdom).

Fax: +(0)1159691300 x 48210

E-mail: ceadams@cochrane-sz.org

Declaration of Interest: None.
}

Thorley et al., 2003). Long term data are remarkably few for an illness that is often life long. There is no persuasive evidence that these drugs really have any effect on the negative symptoms of schizophrenia.

The heady 1960 s gave way to the more cynical 1970 s. Drug patents were running out. The initial justified wave of enthusiasm for antipsychotic medication gave way to the recognition of partial response to medications and a rediscovery of the damaging nature of schizophrenia (Hafner, 2004). This was fertile ground for a pharmaceutical industry, coming of age, wishing to encourage hope of a new pharmacologically-based revolution of treatment of people with schizophrenia. Clozapine, first formulated in the 1960s, was the first in a new generation of drugs. In the 1970s, clozapine was withdrawn in most countries because of blood dyscrasias, but was safely reintroduced with haematological monitoring in the late 1980s (Kane et al., 1988). Clozapine remains a compound with an intriguing effect profile (Tuunainen et al., 2000; Wahlbeck et al., 2000) but its reintroduction was soon followed by marketing of a swathe of new 'atypical' drugs. Initially atypicality was linked with the inability of these drugs to cause catalepsy in rats. However, it became clear that some older generation drugs were found not to cause the rodent effect and that some new ones did. 'Atypical' became synonymous with 'new' or expensive.

New generation drugs were often favourably compared to a toxic older drug (Kennedy et al., 2000). This was considerably contributed to by trial design. All drugs have a dose-event curve. As doses increase positive events also increase, only to plateau. There is a dose beyond which only negative effects occur and more positive outcomes are unlikely (see Figure 1). 


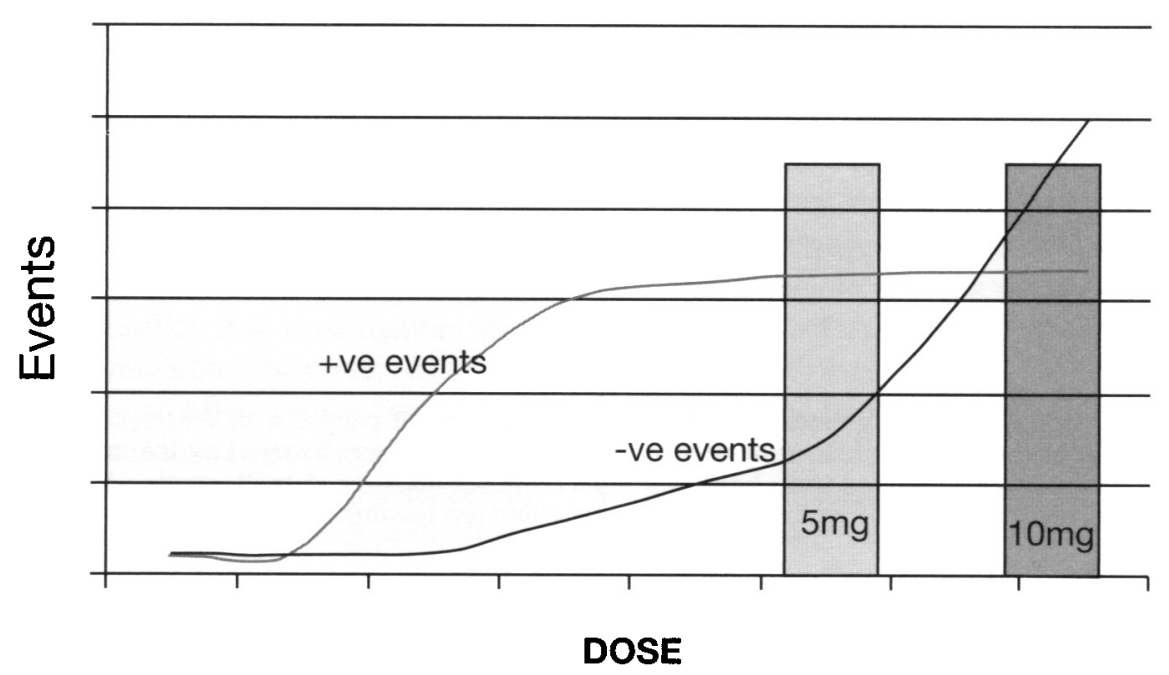

Figure 1. - The dose vs event curve of a hypothetical old generation antipsychotic.

It is perfectly feasible to simply halve or even quarter the dose of a familiar old drug with a wide positive effect plateau, compare it with a dose of known moderate toxicity, and find that the quarter dose is equally clinically effective with a different side effect profile. The new generation drugs were widely advertised as equally clinically effective [as older drugs] but with different adverse effect profiles.

The idea of use of these expensive compounds was successfully sold to a receptive population of clinicians, policy makers and public. The new drugs were moderately effective for schizophrenia but few considered the new generation a welcome expansion of drug treatments rather than a revolution (Centre for Reviews and Dissemination, 2007). Even clinicians in low and middleincome countries were made to feel guilty for not being able to afford the expensive new drugs (Adams et al., 2006).

Reviews undertaken in a systematic and financially disinterested way were rare. They, however, consistently showed the new drugs to have effects - both good and bad - but data to be limited (Duggan et al., 2000), biased (Heres et al., 2006; Kennedy et al., 2000; Montgomery et al., 2004) and often difficult to interpret (Srisurapanont $e t$ al., 2004). In 2002 UK guidelines began to use words carefully when suggesting that atypicals should be ' $a$ ' rather than 'the' first choice for people with schizophrenia (NHS, 2007). Anything but full endorsement has, however, not been entirely welcomed by industry, clinicians, many academics or patients. Nevertheless, moder- ation of wholehearted acceptance of use of atypicals has recently gained further momentum by witnessing industry trying to offset law suits regarding prevalent and damaging adverse effects with large out of court settlements (Dyer, 2007).

There have been calls both for more pragmatic trials to clarify the issue of efficacy of psychotropic medications (Adams, 2002; Thornley \& Adams, 1998; Hotopf et al., 1999) and for studies with more independent funding (Heres et al., 2006; Montgomery et al., 2004). Two recent landmark independently funded semi-pragmatic trials, CATIE (Lieberman et al., 2005) and CUtLASS (Jones et al., 2006), addressed issues of antipsychotic discontinuation along with efficacy and adverse effects. We extracted data for CATIE's primary outcome (leaving the study early) from Cochrane reviews relevant to the comparison drugs (Duggan et al., 2005; El-Sayeh \& Morganti, 2006; Hartung et al., 2005; Jayaram et al., 2006; Mota et al., 2002; Soares et al., 2000; Srisuranapont et al., 2004) in both CATIE and CUtLASS, and undertook a before and after comparison (Table I).

For every comparison, data from the new studies only increased precision. In no case did they materially change the impression already available from existing evidence. The increase in precision of the perphenazine result is particularly noticeable. The research community has largely ignored this old antipsychotic and addition of CATIE's data hugely influences the result (Hartung et al., 2005). The other key finding of these important trials - not presented in this table - is that there is little to 
choose between the newer drugs and intelligent use of older antipsychotics. This applies to both positive and negative effects. The results of these two new independent trials highlight what has been apparent from less disinterested sources for years.
The most certain thing we know about new and old generation antipsychotic drugs is that most patients will choose to stop them within a matter of weeks. In terms of positive effects there is littlie to choose between these drugs and all have frequent negative effects that can be serious.

Table I. - Data for CATIE's primary outcome taken from all relevant trials before and after CATIE and CUtLASS - the risperidone data.

\begin{tabular}{llccccc}
\hline Risperidone vs & & $\begin{array}{c}\text { Number } \\
\text { of trials }\end{array}$ & $\begin{array}{c}\text { Experiemntal } \\
\mathbf{n} / \mathbf{N}\end{array}$ & $\begin{array}{c}\text { Control } \\
\mathbf{n} / \mathbf{N}\end{array}$ & RR & 95\% CI \\
\hline \multirow{2}{*}{ Olanzapine } & Before & 9 & $228 / 657$ & $174 / 667$ & 1.33 & $(1.14,1.55)$ \\
& After & 12 & $594 / 1178$ & $498 / 1212$ & 1.19 & $(1.10,1.28)$ \\
\hline \multirow{2}{*}{ Quetiapine } & Before & 1 & $59 / 175$ & $176 / 553$ & 1.06 & $(0.83,1.35)$ \\
& After & 3 & $321 / 538$ & $465 / 913$ & 0.92 & $(0.84,1.00)$ \\
\hline \multirow{2}{*}{ Perphenazine } & Before & 1 & $4 / 55$ & $15 / 52$ & 0.88 & $(0.47,1.64)$ \\
& After & 2 & $267 / 396$ & $211 / 313$ & 0.99 & $(0.90,1.08)$ \\
\hline \multirow{2}{*}{ Amisulpride } & Before & 1 & $32 / 113$ & $37 / 115$ & 0.88 & $(0.59,1.31)$ \\
\hline Sulpiride & After & 2 & $41 / 135$ & $40 / 128$ & 1.02 & $(0.58,1.80)$ \\
\hline
\end{tabular}

When Professor Peter Jones, Chair of Psychiatry in Cambridge, UK and principle investigator on CUtLASS, was interviewed regarding the results of his study he suggested that the subspecialty of psychiatry - and perhaps policy makers and service users as well - had not been so much "duped" by industry as much as "beguiled" (Vedantam, 2007). This gentle and charming comment carries within it both warning and rebuke. Perhaps industry, with huge pecuniary interests at stake, would dupe clinicians, researchers, patients and opinion leaders if they had to. Perhaps industry does (Heres et al., 2006; Montgomery et al., 2004). However, every bit as concerning is the uncomfortable evidence convicting a speciality guilty of complacency; a speciality, perhaps wanting - for mixed motives - to be beguiled or seduced. The data were always there to be seen.

Part of intelligence is to learn from experience. Individually and collectively there is much to be learnt from the experience of the new generation antipsychotics. Psychiatric treatments should be scientifically evaluated and these evaluations critically appraised with patient care in mind. No one, no institution and no subspecialty is above seduction and it is important to remain wary of being beguiled by good intentions, false hope, fashion and mammon.

\footnotetext{
' Dupe - to fool or hoax

${ }^{2}$ Beguile - to influence by slyness; to attract; cause to be enamoured (www.websters-online-dictionary.org)
}

Acknowledgements. The authors are ever grateful to Professor Alex Jadad (University of Toronto) for the idea for figure 1. Thank you to Tessa Grant and Akhil Abhijnhan for comments on the manuscript.

\section{REFERENCES}

Adams C.E. (2002). Schizophrenia trials: past, present and future. Epidemiologia e Psichiatria Sociale 11, 144-1451.

Adams C.E., Tharyan P., Coutinho E.S. \& Stroup T.S. (2006). The schizophrenia drug-treatment paradox: pharmacological treatment based on best possible evidence may be hardest to practise in high-income countries. British Journal of Psychiatry 189, 391-392.

Begg C., Cho M., Eastwood S., Horton R., Moher D., Olkin I., Pitkin R., Rennie D., Schulz K.F., Simel D. \& Stroup D.F. (1996). Improving the quality of reporting of randomized controlled trials. The CONSORT statement. Journal of American Medical Association 276, 637-639.

Centre for Reviews and Dissemination (2007). Drug treatments for schizophrenia - Effective Health Care Bulletin. Retrieved June 4, 2007, from http://www.york.ac.uk/inst/crd/ehc56.htm

Duggan L., Fenton M., Dardennes R.M., El-Dosoky A. \& Indran S. (2000). Olanzapine for schizophrenia. Cochrane Database of Systematic Reviews, Issue 2.

Duggan L., Fenton M., Rathbone J., Dardennes R., El-Dosoky A. \& Indran S. (2005). Olanzapine for schizophrenia. Cochrane Database of Systematic Reviews, Issue 2.

Dyer O. (2007). Lilly investigated in US over the marketing of olanzapine. British Medical Journal 334, 171

El-Sayeh H.G. \& .Morganti C. (2006). Aripiprazole for schizophrenia. Cochrane Database of Systematic Reviews, Issue 2.

Freeman H. (1958). The tranquilising drugs. In Schizophrenia: A Review of the Syndrome (ed. L. Bellak). Logos Press: New York.

Hafner H. (2004). Schizophrenia: still Kraepelin's dementia praecox? Epidemiologia e Psichiatria Sociale 13, 99-112.

Hartung B., Wada M., Laux G. \& Leucht S. (2005). Perphenazine for schizophrenia. Cochrane Database of Systematic Reviews, Issue 1.

Heres S., Davis J., Maino K., Jetzinger .E, Kissling W. \& Leucht S. (2006). Why olanzapine beats risperidone, risperidone beats queti- 
apine, and quetiapine beats olanzapine: an exploratory analysis of head-to-head comparison studies of second-generation antipsychotics. American Journal of Psychiatry 163, 185-194.

Hotopf M., Churchill R. \& Lewis G. (1999). Pragmatic randomised controlled trials in psychiatry. British Journal of Psychiatry 175, 217-223.

Jayaram M.B., Hosalli P. \& Stroup S. (2006). Risperidone versus olanzapine for schizophrenia. Cochrane Database of Systematic Reviews, Issue 2.

Jones P.B., Barnes T.R., Davies L., Dunn G., Lloyd H., Hayhurst K.P., Murray R.M., Markwick A. \& Lewis S.W. (2006). Randomized controlled trial of the effect on Quality of Life of second- vs first-generation antipsychotic drugs in schizophrenia: Cost Utility of the Latest Antipsychotic Drugs in Schizophrenia Study (CUtLASS 1). Archives of General Psychiatry 63, 1079-12087.

Joy C.B., Adams C.E. \& Lawrie S.M. (2006). Haloperidol versus placebo for schizophrenia. Cochrane Database of Systematic Reviews 2006, Issue 4.

Kane J., Honigfeld G., Singer J. \& Meltzer H. (1988). Clozapine for the treatment-resistant schizophrenic. A double-blind comparison with chlorpromazine. Archives of General Psychiatry 45, 789-796.

Kennedy E., Song F., Hunter R., Clarke A. \& Gilbody S. (2000). Risperidone versus typical antipsychotic medication for schizophrenia. Cochrane Database of Systematic Reviews, Issue 2.

Lieberman J.A., Stroup T.S., McEvoy J.P., Swartz M.S., Rosenheck R.A., Perkins D.O., Keefe R.S., Davis S.M., Davis C.E., Lebowitz B.D., Severe J., Hsiao J.K. \& Clinical Antipsychotic Trials of Intervention Effectiveness (CATIE) Investigators (2005). Effectiveness of antipsychotic drugs in patients with chronic schizophrenia. New England Journal of Medicine 353, 1209-1223.

Marques L.O., Lima M.S. \& Soares B.G. (2004). Trifluoperazine for schizophrenia. Cochrane Database of Systematic Reviews, Issue 1.

Matar H. \&.Almerie M. (2007). Oral fluphenazine versus placebo for schizophrenia. Cochrane Database of Systematic Reviews, Issue 1.
Montgomery J.H., Byerly M., Carmody T., Li B., Miller D.R., Varghese F. \& Holland R. (2004). An analysis of the effect of funding source in randomized clinical trials of second generation antipsychotics for the treatment of schizophrenia. Controlled Clinical Trials 25, 598612.

Mota N.E., Lima M.S. \& Soares B.G. (2002). Amisulpride for schizophrenia. Cochrane Database of Systematic Reviews, Issue 2.

NHS National Institute for Clinical Excellence (2007). Schizophrenia: NICE guideline. Retrieved June 4, 2007, from http://www.nice.org. uk/guidance/CGl/niceguidance/pdf/English

Soares B.G., Fenton M. \& Chue P. (2000). Sulpiride for schizophrenia. Cochrane Database of Systematic Reviews, Issue 2.

Srisurapanont M., Maneeton B. \& Maneeton N. (2004). Quetiapine for schizophrenia. Cochrane Database of Systematic Reviews, Issue 2 .

Thornley B. \& Adams C. (1998). Content and quality of 2000 controlled trials in schizophrenia over 50 years. British Medical Journal 317, $1181-1184$.

Thornley B., Rathbone J., Adams C.E. \& Awad G. (2003). Chlorpromazine versus placebo for schizophrenia. Cochrane Database of Systematic Reviews, Issue 2.

Turner T. (2007). Chlorpromazine: unlocking psychosis. British Medical Journal 334, Suppl 1, s7.

Tuunainen A., Wahlbeck K. \& Gilbody S.M. (2000). Newer atypical antipsychotic medication versus clozapine for schizophrenia. Cochrane Database of Systematic Reviews, Issue 2.

Vedantam S. (2006). In antipsychotics, newer isn't better - drug find shocks researchers. Washington Post, Tuesday, October 3, 2006. Retrieved June 4, 2007, from http://www.washingtonpost.com/wpdyn/content/article/2006/10/02/AR2006100201378.html

Wahlbeck K., Cheine M. \& Essali M.A. (2000). Clozapine versus typical neuroleptic medication for schizophrenia. Cochrane Database of Systematic Reviews, Issue 2. 